\title{
Barriers in Employee Effective Training and Learning
}

Syeda Rida-E-Fiza

Economics, International Islamic University Islamabad, Pakistan

Muhammad Farooq

Associate Professor of Sociology Department of Sociology Pir Mehr Ali Shah Arid Agriculture University Rawalpindi

Faria Ibad Mirza

Lecturer in Sociology, Department of Sociology, Pir Mehr Ali Shah Arid Agriculture University Rawalpindi

Fara Riaz

Lecturer, Institute of Rural Home Economics, University of Agriculture Faisalabad

Shamas-Ud-Din

Medical Social Welfare Officer, Shaheed Zulfiqar Ali Bhutto Medical University, PIMS Hospital Islamabad

\section{Doi:10.5901/mjss.2015.v6n3s2p240}

\section{Abstract}

Employee training and development enables employees to develop skills and competencies necessary to enhance bottom-line results for their organization. They may not see the immediate results of training on their return on investment, although training is crucial to the long-term prosperity of any business. In times of economic hardship, training is seen as an additional expense rather than as an investment in a business' future. So understanding the barriers to effective training before implementing training methods can save businesses time and money. To measure the learning barriers, the research used the framework developed by Darkenwald and Merriam (1982). The research used a convenient Sampling Method. The women in Islamabad are chosen as target for the research. Who have the average ICT skills but the women working at a supervisory position were having good ICT skills. Women of Islamabad are actually lacking in the learning ability. Working women in Islamabad are lower than expected, even though they do not face serious learning barriers.

Keywords: Employee training, Skill development, barriers on training, Darkenwald and Merriam model

\section{Introduction}

Pakistan is a multi-ethnic, multi-cultural and multi-lingual society. The total population of Pakistan is over186 million consisting of $51.245 \%$ of males in majority, $48.50 \%$ of women (Department of Statistics Pakistan 2014). Pakistan is highly populated country with conservative minded society. After 67 years of independence from the India, Pakistan is still struggling for being developed one (Muhammad and Sohail, 2012). While mapping the speed of $21^{\text {st }}$ century Pakistan had geared its well settled efforts toward Information Communication Technology (ICT). According to annual report of performance, Pakistan had over 20 million internet users and is ranked as one of the top countries that have registered a high growth rate in internet dissemination in 2013. Overall, it has the 15th largest population of internet users in the world. In the fiscal year 2012-2013, the Government of Pakistan aims to spend Rs. 4.6 billion on information technology projects, with emphasis on e-government, human resource and infrastructure development. Similarly The World Economic Forum also assessed the development of Information and Communication Technology in the country, ranked Pakistan 102nd among 144 countries in the Global Information Technology report of 2012-2013.

Besides these rankings, it has been widely recognized in Pakistan that the creation of a highly skilled workforce is one of the key avenues to improving productivity and international competitiveness, including fostering social capital. Thus it is not surprising that we have witnessed a renewed focus on education and training during the last decade or so. 
The benefits of this focus, of course, go well beyond improvements in the ability of our economy to compete. Importantly, increased learning opportunities typically benefit those individuals who are able to gain access to such training. Most obviously, training is usually assumed to provide workers with increased promotional opportunities, improved job security and higher wages. Employee training and development enables employees to develop skills and competencies necessary to enhance bottom-line results for their organization. (Moore; 2004) They may not see the immediate results of training on their return on investment, although training is crucial to the long-term prosperity of any business. In times of economic hardship, training is seen as an additional expense rather than as an investment in a business' future. So understanding the barriers to effective training before implementing training methods can save businesses time and money. (Koshal, et al., 1998)

Despite the significant growth in ICT professionals, there remains a gender imbalance. The well observed fact is that certain segments of the population are still underrepresented in ICT. Among those who are being underrepresented are women (Palma, 2001; Trautho, 2002; Wilson-Kovacs et al., 2006). Many of the previous studies were done on the idea that males and females have different technology related attitudes, behaviors and skills (Broos, 2005; Woodfield, 2002). Studies have often hypothesized that computers appeal more to men and boys than to women and girls and therefore males are more likely to have had more computer related experience. Hence women's are less prone to ICT advancement and usage, but not all, this trend is more to non-supervisory level women than to supervisory level women (junaidah; 2008). This study visualized the same fact that women's at non-supervisory level are less acquired with ICT skills than women at supervisory level. For this purpose scientific research has been conducted and the capital of Pakistan (ISLAMABAD) is taken as sample. As Islamabad is the more developed city of Pakistan, with the women's labor force participation rate of $52 \%$ as compared to other cities (GOV. 2012-13).

Information communication technology (ICT) is very vital in life. On the contrary in past majority of studies were qualitative in nature, which was conducted through case studies and interviews (Smith 1997; Moran 1998; Gibb 1999). An exception to the mostly qualitative research attempt in this area has been the series of inquisitions conducted over a number of years by a group of research interests. While in this research, efforts are made to conduct the research using quantitative techniques and different approaches are used with specific model. Irrespective of gender, linguistic, culture and demography it would be advantageous for all individuals in society everywhere to acquire basic ICT skills. Despite significant growth in ICT professionals in the last decade, there still remains a gender imbalance, particularly in developing countries such as Pakistan. This study can be generalized, and can be effectively used for the authorities to lower the gap of ICT skills between man and women in Pakistan.

\section{Major Factors Influencing Employees Training and their Development}

The quality of employees and their development through training and education are major factors in determining longterm profitability of a small business. If a firm hires and keeps good employees, it is good policy to invest in the development of their skills, so they can increase their productivity. Training often is considered for new employees only. This is a mistake because ongoing training for current employees helps them adjust to rapidly changing job requirements (GOV. 2012-13).

\section{Purpose of Training and Development}

The purpose of formulating a training strategy is to answer two relatively simple but vitally important questions: (1) what is our business? And (2) what should our business be? Armed with the answers to these questions and a clear vision of its mission, strategy and objectives, a company can identify its training needs. Setting goals helps to evaluate the training program and also in motivation of employees. Allowing employees to participate in setting goals increases the probability of success (GOV.1998).

\section{Objectives}

Objective of study is to explore the factors influencing the amount and type of training and learning that occurs in organizations and to find ways of removing those barriers. The topic was selected keeping in view the constraints in the Training and Development field and how the constraints can be minimized in the Pakistani perspective. Employee Training and Development is essential to the ongoing success of every organization. Although technology and the internet have enabled global collaboration and competition, people are the organization's competitive advantage. 


\section{Research Questions}

1. How can effective training help employees to become more competent within intercultural contexts?

2. How to remove the training barriers that the top management should involve in training, so that they can lead there managerial team effectively?

3. Identifying the organizational learning barriers affects the learning skills of employee which leads them to excel their skills and abilities?

4. Would information communication technology helpful in removing learning barriers among working women in Islamabad?

\section{Literature Review}

The previous study developed an understanding of the problems and challenges that a trainee and trainer come across in this field. The support of top management is necessary to eliminate the potential barrier (perceptual, emotional, motivational, and cognitive) which affected managers and other mid-career manager participation in organization. (Martin McCracken, 2005).

Research and Training are the pillars to eliminate the age diversity phenomena. Age diversity has become an important factor for companies in the attraction and recruitment of staff. The age factor and its role in training provided and knowledge gained from that training program. Mostly training programs are not offered to old age workers.(Becci, 2006).

Providing a learning frame work in an organization in that way the worker learns more from organization. (Fides Matzdorf, Mike Green, 2000).

And it is analyzed that to improve employees behavior in intercultural situations, effective training programs must allow the individuals to develop cognitive, effective and behavioral area. (Graf, A. (2004)).

It raised issues in the provision of training. Get the results of clear indications of a "global convergence of concern". It seems that trainers, wherever they are based, are facing the same or similar problems (Martyn Sloman, Toni Borsattino, 2005).

A study at a multinational corporation indicated that barriers to employee knowledge sharing in communities of practice are lack of confidence, non-supportive organizational culture and distrust and to solve this problem they identified various types of trusts (Ardichvili et al, 2003).

The modern era has the unique invention of Information communication Technology. The barriers in adopting Information Communication Technology for the working women and identify the ICT skills by possessing their usage, adoption characteristics, adopters' categories, and to establish the relationships among these constructs (Jumaidah Hashim, 2008). Despite considerable growth in the ICT profession, there remains a gender imbalance in the participation of women in ICT (Adya and Kaiser, 2005). Most of the literature about women's participation indicates that there is great resistance and hurdles created to promote women to top positions (Ariffin, 1995). On the other side, according to Crump et al. (2007) most of women do not vigorously hunt for to be employed in ICT. Not only their participation is low as compared to their male counterpart, but according to Trauth (2002) there exist gender differences also in computer skills and usage.

The barriers which are faced by women's in ICT adoption are identified four general categories of learning barriers (Darkenwald and Merriam 1982). The barriers are situational barriers, institutional barriers, informational barriers, and psychological barriers. Some of the previous studies in this regard also show significantly these barriers, more elaborately. For instance, Cross and Linhen (2006) identified the organizational policies, practices, networking, monitoring and self imposed glass ceiling are the barriers faced by women by preventing them from advancing in high-tech sector. While Evan (1995) also found that many women are prevented from pursuing IT skills because the time and family commitment often comes at the expense of their learning. Lack of partner support and financial problem are also the major barriers faced by the women. Some other factors are also very influential as, the study by kailassa and illyas (2005) depicted that social and structural barriers are determinant in women's career to ICT skills. Social factors include gender stereotyping, role models, access to technology. Another study by Baker et al. (2007) found that social factors affect the use of IT but cultural factors are also dominating ones. Another study by liu and Wilson (2001) identified five barriers to women learning and usage of ICT. These include family responsibility, gender stereotypes and attitude, working time constraints, lack of confidence and lack of IT skills. There are myths and the psychological aspects of society, creates major barriers to women. As Palma (2001) found that women had anxiety to computer learning and females are more prone or segregated to the sex-typed 'women's job' like medicine, law, teaching. In another study by Broos (2005) related 
to computer anxiety depicts that computer self-efficacy as an important factor in office for gender difference related to ICT use. Women lack basic literacy and computer skills. There is no doubt that basic literacy and numeric are needed to read and compose simple messages, navigate the internet, and execute commands in software applications.

ICT cannot produce any outcome unless it is adopted and used effectively. To use ICT, one must at least possess some basic ICT skills. Few studies have examined the relationship between ICT skills and IT adoption. Shiels et al (2003) for example, asserted that strong IT capabilities including the specific ICT skills have considerable influence in adopting ICT. Wainwright et al. (2005) added that managerial ICT skills, ICT knowledge, and ICT practices are important determinants of whether IT is adopted or rejected by the potential users. Learning enables the possession of those skills.

In a previous study (rogers, 1995) theory of innovation by Rogers indicates factors that influence adoption of an innovation and the theory of individual innovation and the theory of perceived attributes because they help to understand the relationship between the innovator characteristics and the adopters' categories.

\section{Data Source}

This research used a self-developed questionnaire to measure the learning barriers and Information Communication and Technology adoption. The questionnaires were administered face-to-face to a total of 40 working women in Islamabad, who participated as respondents in this research. Those consequences were then coded and SPSS software is then used as numerical implications.

\section{Model Used}

To measure the learning barriers, the research used the framework developed by Darkenwald and Merriam (1982). The author has identified four general categories of learning barriers in adult learning, which are:

- Situational barriers

- Institutional barriers

- Informational barriers

- Psychological barriers.

Situational barriers relate to an individual's life context at a particular time, that is, the realities of one's goal and physical environment. For example, cost, lack of time, lack of transportation, lack of childcare and geographical isolation.

Institutional barriers are such as inconvenient schedules, restrictive locations, and the like. Other significant institutional barriers are lack of attractive or appropriate courses and institutional policies and practices that impose inconvenient, confusion, or frustration on adult learners.

Informational barriers are sometimes constructed simply to mean institutional failure in communicating information on learning opportunities to adults.

Psychological barriers are individually held beliefs, values, attitudes, or perceptions that inhibit participation in organized learning activities.

\section{Methodology}

Learning barriers in adopting ICT among selected working women in Islamabad

\section{Design/Methodology/Approach}

The research used a convenient Sampling Method. The enumerators approached the working women and asked them to respond to the questionnaires. They waited for the respondents to complete the questionnaire and collected them immediately.

This research hypothesizes the following:

H1. There is a relationship between learning barriers and ICT skills.

$H 2$. There is a relationship between learning barriers and ICT usage at workplace.

H3. There is a relationship between learning barriers, ICT skills, and ICT usage with innovation characteristics.

H4. There is a relationship between learning barriers, ICT skills, and ICT usage with adopters' categories.

The survey instrument was developed from the constructs used in the individual innovativeness theory and the theory of perceived attributes. 
Theory of perceived attributes: The theory of perceived attributes is based on the view that individuals will adopt an innovation if they perceive that the innovation has the following attributes. First, the innovation must have some relative advantage over an existing innovation or the status quo. Second, it is important for the innovation to be compatible with existing values, past experience, and practices of the potential adopter. Third, the innovation cannot be too complex or perceived as difficult to understand. Fourth, the innovation must have trial ability; whereby it can be tested for a limited period of time without adoption. Fifth, the innovation must offer observable results (Rogers, 1995). Rogers further asserted that an adopter's experience with one innovation influences that individual's perception towards the next innovation in a technology cluster to diffuse through the individual's system. Thus, if adopters have a negative first experience with one computer application, they may consider all computer applications unfavorable from this perspective.

Individual innovativeness theory: The individual innovativeness theory is based on who adopts the innovation and when. The first category of adopters is innovators. Innovators are the risk-takers and pioneers who lead the way. Innovators are able to adopt an innovation with a high degree of uncertainty about it at the time of adoption, and are willing to accept an occasional setback when a new idea proves unsuccessful. The second group is known as the early adopters. Early adopters climb on board the train early and help spread the word about the innovation to others. The third group is the early majority. The early majority are convinced and influenced by the innovators and early adopters. They may deliberate for some time before completely adopting a new idea. Their innovation-decision period is relatively longer than that of the innovator and early adopter. The fourth group is the late majority. The late majority wait to make sure that adoption is in their best interests. They approach innovation cautiously and they do not adopt until most others have done so. The final group is laggards. These are the individuals who are highly skeptical and resist adopting until absolutely necessary (Rogers, 1995).

This theoretical framework helps to understand the reasons IT is adopted by some individuals and not by others. This theory can explain, predict, and account for factors that increase or impede the diffusion of innovations.

Each questionnaire consists of six parts.

(a) Respondent's background, it has questions regarding respondent's position, age, gender, race, and highest educational attainment.

(b) Information and communication technology skills, it has questions about the basic skill, skill to use email, skill to use CD-ROM and skill to use internet of the respondents.

(c) While for ICT usage at work place, questions were posted on the internet usage, CD-ROM usage, and email usage at the work place.

(d) For innovation characteristics, it has questions on the five innovation characteristics proposed in the research: relative advantage, compatibility, complexity, trialability, and observability.

(e) For adopters' categories, questions were asked to the respondents in order to identify their adopter category.

(f) The final part has items for examining the learning barriers.

\subsection{Respondents' background}

There were 40 working women who participated in this research. As shown in Table1; about 62 per cent of the respondents are in non-supervisory positions (production operators, supporting staffs, and clericals), while 37.5 per cent are in supervisory positions (supervisors, executives and managers). Two per cent of the respondents are, of young age with more than 25 per cent aged below 35 years old. About 60 per cent completed high schools, 35 per cent graduated with a diploma, and 4.1 per cent are degree holders.

The education variable was negatively correlated to learning barrier $(r=-0.447 ; p=0.000)$. The higher the education qualification obtained by the respondents, the lesser learning barriers they faced in adopting ICT.

Table 1. Distribution of respondent's background $(n=40)$

\begin{tabular}{|c|c|c|c|}
\hline Variable & Label & Frequency & Percentage \\
\hline \multirow[t]{2}{*}{ Position } & Non-supervisory & 25 & 62.5 \\
\hline & Supervisory & 15 & 37.5 \\
\hline \multirow[t]{4}{*}{ Race } & Punjabi & 18 & 45 \\
\hline & Sindhi & 12 & 23.6 \\
\hline & Balochi & $\overline{8}$ & 19.7 \\
\hline & $\overline{\text { Others }}$ & $\overline{2}$ & $\overline{5}$ \\
\hline
\end{tabular}




\begin{tabular}{||c||c||c|c|}
\hline \multicolumn{1}{|c|}{ Age } & 25 years old & 1 & 2.5 \\
\hline \hline & $25-35$ years old & 10 & 25 \\
\hline \hline & $36-45$ years old & 20 & 50 \\
\hline \hline & $46-55$ years old & 8 & 19.7 \\
\hline \hline & 55 years old & 1 & 2.5 \\
\hline \hline Education & Primary school & 2 & 5 \\
\hline \hline & High school & 24 & 60 \\
\hline \hline & Diploma & 10 & 35 \\
\hline \hline & Bachelor degree & 20 & 25.7 \\
\hline \hline & Master degree & 35 & 4.1 \\
\hline & Others & 1 & 1.3 \\
\hline
\end{tabular}

\subsection{Learning barriers}

Four learning barriers are examined in this study. They are situational barrier, institutional barrier, informational barriers, and psychological barrier. Descriptive statistics in "Table 2" shows that the respondents disagreed that they face some of these learning barriers (mean 2.491). For situational barriers, the respondents in the supervisory positions faced lesser learning barriers (mean 2.157) as compared to the respondents in the non-supervisory positions (mean 2.652), and the difference in mean is significant $(p=0.000)$.

Table 2: Learning Barriers

\begin{tabular}{|c|c|c|c|c|c|}
\hline & $\mathbf{N}$ & Mean & SD & t-value & p-value \\
\hline \hline Situational & 40 & 2.407 & 0.750 & 3.968 & 0.000 \\
\hline \hline (a)Non-supervisory & 25 & 2.652 & 0.922 & & \\
\hline \hline (b)Supervisory & 15 & 2.157 & 0.789 & & \\
\hline \hline Institutional & 40 & 2.576 & 0.907 & 1.337 & 0.182 \\
\hline \hline (a)Non-supervisory & 25 & 2.776 & 0.718 & & \\
\hline \hline (b)Supervisory & 15 & 2.646 & 0.612 & & \\
\hline \hline Learning Barriers & 40 & 2.491 & 0.763 & 4.615 & 0.000 \\
\hline \hline (a)Non-supervisory & 25 & 2.628 & 0.646 & & \\
\hline
\end{tabular}

\subsection{Information and communication technology skills}

The objective of this study among others is to examine the ICT skills (basic computer skill, e-mail skill, CD-ROM skill, and internet skill) possessed by the selected working women in ISLAMABAD. The results in "Table 3" show that the respondents have ICT skills slightly above average (mean 3.301). The independent samples test showed that there is a difference in mean score between the non-supervisory and the supervisory, and the difference is statistically significantly. The respondents in the supervisory positions possess good ICT skills and their ICT skills are higher (mean 4.105) than the respondents in the non-supervisory positions (mean 3.092). 
Table 3. ICT skill

\begin{tabular}{||c|c|c|c|c|c||}
\hline & $\mathbf{N}$ & Mean & SD & t-value & p-value \\
\hline \hline Basic skill & 40 & 3.270 & 1.0702 & -4.218 & 0.00 \\
\hline \hline (a)Non-supervisory & 25 & 3.144 & 1.104 & & \\
\hline \hline (b)Supervisory & 15 & 3.756 & 0.760 & & \\
\hline \hline E-mail & 40 & 3.475 & 1.401 & -6.401 & 0.00 \\
\hline \hline (a)Non-supervisory & 25 & 3.232 & 1.404 & & \\
\hline \hline (b)Supervisory & 15 & 4.408 & 0.920 & & \\
\hline \hline Internet & 40 & 3.260 & 1.415 & -6.814 & 0.00 \\
\hline \hline (a)Non-Supervisory & 25 & 3.001 & 1.402 & & \\
\hline \hline (b)Supervisory & 15 & 4.256 & 0.955 & & \\
\hline \hline ICT skills & 40 & 3.301 & 1.218 & -6.333 & 0.00 \\
\hline \hline (a)Non-Supervisory & 25 & $\underline{3.092}$ & 1.226 & & \\
\hline \hline (b)Supervisory & 15 & $\underline{4.105}$ & 0.780 & & \\
\hline
\end{tabular}

\subsection{ICT usage at workplace}

For the ICT usage at workplace, the respondents were asked to indicate how often they use the internet, CD-ROM, and e-mail at their workplace. "Table 4" shows that the respondents almost seldom (mean 2.526) use the internet and e-mail at their workplace.

Table 4. The independent samples test for ICT usage

\begin{tabular}{|c|c|c|c|c|c|}
\hline & $\mathbf{N}$ & Mean & SD & t-value & p-value \\
\hline \hline Internet usage & 40 & 2.019 & 0.951 & -1.722 & 0.086 \\
\hline \hline CD-ROM usage & 40 & 2.450 & 1.163 & -1.612 & 0.108 \\
\hline \hline E-mail usage & 40 & 3.120 & 1.557 & -5.643 & 0.000 \\
\hline ICT usage & 40 & $\mathbf{2 . 5 2 6}$ & 1.061 & -3.813 & 0.000 \\
\hline
\end{tabular}

\subsection{Innovation characteristics}

The literature has identified five innovation characteristics. These are the dimensions for why innovation was adopted by the respondents. The dimensions are:

$>$ Relative advantage,

$>$ Compatibility,

$>$ Complexity,

$>$ Trialability, and

$>$ Observability.

Referring to "Table 5"; "complexity" was identified as the most prevalent innovation characteristics with the highest mean (mean 4.171) among the respondents. Both of the groups; the non-supervisory and supervisory find it difficult to adopt IT. The respondents in the supervisory positions agreed that they have relative advantage (mean 4.146), compatibility (mean 4,003), and trialability (mean 4.043) of the innovation. 
Table 5. Innovation

\begin{tabular}{|c|c|c|c|c|c|}
\hline & $\mathbf{N}$ & Mean & SD & t-value & p-value \\
\hline \hline Relative advantage & 40 & 3.497 & 1.122 & -5.465 & 0.000 \\
\hline \hline (a)Non-supervisory & 25 & 3.329 & 1.131 & & \\
\hline \hline (b)Supervisory & 15 & 4.146 & 0.811 & & \\
\hline \hline Trialability & 40 & 3.491 & 1.018 & -5.104 & 0.000 \\
\hline \hline (a)Non-supervisory & 25 & 3.347 & 1.031 & & \\
\hline \hline (b)Supervisory & 15 & 4.043 & 0.750 & & \\
\hline \hline Complexity & 40 & 4.171 & 0.596 & -3.586 & 0.000 \\
\hline \hline (a)Non-supervisory & 25 & 4.411 & 0.603 & & \\
\hline \hline (b)Supervisory & 15 & 4.403 & 0.509 & & \\
\hline \hline Observability & 40 & 3.653 & 0.768 & -4.051 & 0.000 \\
\hline \hline (a)Non-supervisory & 25 & 3.566 & 0.747 & & \\
\hline \hline (b)Supervisory & 15 & 3.989 & 0.758 & & \\
\hline \hline Innovation characteristics & 40 & 3.703 & 0.719 & -5.848 & 0.000 \\
\hline (a)Non-supervisory & 25 & 3.588 & 0.710 & & \\
\hline (b)Supervisory & 15 & 4.145 & 0.573 & & \\
\hline
\end{tabular}

\subsection{Adopters' categories}

The adopters' categories discussed in the literature are innovators, early adopters, early majority, late majority, and laggards. The results in "Table 6" illustrate that the group's highest mean score was for innovator (mean 3.524). The second highest mean score was for early majority (mean 3.358). The respondents in the supervisory group score highest in the innovator category as well. The independent samples test shows that there is a difference in mean between the two groups; the non-supervisory and the supervisory, and the difference is statistically significant $(p=0.000)$. Innovators are able to adopt with a high degree of uncertainty about an innovation at the time of adoption, and are willing to accept an occasional setback when a new idea proves unsuccessful. For the early majority group, they may deliberate for some time before completely adopting a new idea.

Table 6. Adopters'

\begin{tabular}{|c|c|c|c||c||c||}
\hline & $\mathbf{N}$ & Mean & SD & t-value & p-value \\
\hline \hline Innovators & 40 & 3.524 & 0.926 & -5.291 & 0.000 \\
\hline \hline (a)Non-supervisory & 25 & 3.389 & 0.947 & & \\
\hline \hline (b)Supervisory & 15 & 4.044 & 0.608 & & \\
\hline \hline Late majority & 40 & 3.274 & 0.859 & -1.535 & 0.126 \\
\hline \hline (a)Non-supervisory & 25 & 3.236 & 0.839 & & \\
\hline \hline (b)Supervisory & 15 & 3.419 & 0.925 & & \\
\hline \hline Early majority & 40 & 3.358 & 0.948 & -1.830 & 0.068 \\
\hline \hline (a)Non-supervisory & 25 & 3.308 & 0.973 & & \\
\hline \hline (b)Supervisory & 15 & 3.549 & 0.826 & & \\
\hline \hline Adopters' categories & 40 & 3.315 & 0.734 & -3.582 & 0.000 \\
\hline (a)Non-supervisory & 25 & 3.311 & 0.761 & & \\
\hline (b)Supervisory & 15 & 3.671 & 0.537 & & \\
\hline
\end{tabular}




\subsection{Learning barriers as predictor to ICT innovation and adoption}

The results in "Table 7"; "Table 8"; and "Table 9" support the research hypotheses. It is shown that learning barriers are negatively correlated to ICT skills $(r=-0.679, p=0.000)$. Similarly ICT usage, is negatively correlated with learning barriers $(r=-0.621, p=0.000)$. At the same time, learning barriers are negatively related to innovation characteristics $(r=-0.688$, $p=0.000)$. Learning barriers are also negatively related to adopters' categories $(r=-0.523, p=0.000)$. Moreover, learning barriers, ICT skills, and ICT usage accounted for 70 per cent variation in innovation characteristics. Meanwhile, for adopters' categories, 43 per cent variation is accounted for by the learning barriers, ICT skills, and ICT usage.

Table 7. Correlation analysis of the studied variables

\begin{tabular}{|c|c|c|c|c|}
\hline Variable & $\boldsymbol{\alpha}$ & Mean & SD & \\
\hline \hline 1.LEA BARR & 0.860 & 2.491 & 0.763 & - \\
\hline \hline 2.ICT SKILL & 0.974 & 3.301 & 1.218 & $-0.679^{\star \star}$ \\
\hline \hline 3.ICT USE & 0.942 & 2.526 & 1.061 & $-0.621^{\star \star}$ \\
\hline \hline 4.INNO CHAR & 0.978 & 3.703 & 0.719 & $-0.688^{\star \star}$ \\
\hline 5.ADDOP CAT & 0.920 & 3.385 & 0.734 & $-0.523^{\star \star}$ \\
\hline
\end{tabular}

Notes: *^p, 0.001; LEABARR = learning barriers; ICT SKILL =ICT skills; ICT USE = ICT usage; INNO CHAR = innovation characteristics; ADOPPCAT = Adopters' category

Table 8. Regression analysis predicting innovation characteristics

\begin{tabular}{|c||c||c|c|}
\hline Independent variables & $\boldsymbol{\beta}$ & t-value & $\mathrm{p}$-value \\
\hline \hline Learning barriers & -0.229 & 25.336 & $0.000^{*}$ \\
\hline \hline ICT skills & 0.499 & 9.061 & $0.000^{*}$ \\
\hline ICT usage & 0.193 & 3.741 & $0.000^{*}$ \\
\hline
\end{tabular}

Notes: Dependent Variable: innovation characteristics; ${ }^{*}$ statistical significant at $p, 0.05 ; R^{2}=0.701 ;$ Adjusted $R^{2}=0.698 ; F=$ 243.368; Sig $=0.000$.

Table 9. Regression analysis predicting adopters' categories

\begin{tabular}{|c|c|c|c|}
\hline Independent Variables & $\boldsymbol{\beta}$ & $\mathrm{t}$-value & $\mathrm{p}$-value \\
\hline \hline Learning barriers & 20.136 & 22.302 & $0.022^{*}$ \\
\hline \hline ICT skills & 0.467 & 6.188 & $0.000^{*}$ \\
\hline ICT usage & 0.113 & 1.598 & $0.111^{*}$ \\
\hline
\end{tabular}

Notes: Dependent variable: adopters' category; statistical significant at $p<0.05 ; R^{2}=0.438 ;$ Adjusted $R^{2}=0.433 ; F=80.853$; Sig $=0.000$

\section{Findings}

It was found that the women in Islamabad have the average ICT skills but the women working at a supervisory position were having good ICT skills. Women of Islamabad are actually lacking in the learning ability. Working women in Islamabad are lower than expected, even though they do not face serious learning barriers. These findings have several important implications. This study provides useful insights to reduce the knowledge gap by identifying ICT skills and ICT usage as predictors to explore ICT adoption among the working women in Islamabad. Even though this study did not examine the attitudes directly, other studies (Cross and Linehan, 2006; Liu and Wilson, 2001) have found that the attitudes of some women actually nourished this problem, which need to change if women are to be seen as competent as men in ICT. In male dominated field such as IT, there exists a doubt if women can ever accomplish the job as men can do. This prevalent bias may discourage many talented women from entering the career field, and prevent those who 
choose to enter from advancing inside their organizations. For the non-supervisory jobs, women need to be IT literate because more women-related jobs such as typists, bank tellers and telephone operators are replaced by the IT. IT has created many jobs and eliminated many others (Michie, 2006; Wilson-Kovacs, 2006). Practically, all jobs in the present day require increasing levels of IT skills. The managers of organization will need to take initiatives to seek for ways to improve the skills of their women employees and to create work environment that build self-efficacy expectations for them. Otherwise, women probably will remain uninspired to fulfill the need to be highly skilled IT workers and managers.

\section{Conclusion}

We come to know various barriers in employee training after our research. Trainers cannot deliver effective training if they do not understand the needs of their trainees. Trainers and managers require knowledge about the skills and weaknesses of staff. With the correct research, training can be customized to the needs of trainees. More generally, managers who do not interact with their team members on a regular basis may find it difficult to evaluate the need for training. A lack of data also is a barrier to effective training. Similar to a lack of direction, it relates to an institutional perspective. A business cannot learn from its training successes without adequate data about previous training sessions in the form of employee feedback, reports on progress and impact on organizational growth figures. Formal evaluation of training after the training takes place is crucial for obtaining and maintaining this data. Access to such data can save time and money when a business plans new training activities.

Lack of team spirit and poor communication can undermine learning and development because most forms of learning occur through communication between managers and employees. Training is ineffective if staff is not motivated about participating openly in group activities. It is the manager's responsibility to encourage employees to develop so that they feel they will benefit from training. Regular interaction is important to ensure managers are aware of exactly what kinds of training different employees require. Open communication is vital for encouraging employees.

For future research direction, it would be interesting to discover the reasons for low ICT skills among working women and how this has affected their job performance. Furthermore, future researches could examine what efforts organizations have taken to improve the women employees' ICT skills. It is also interesting to know if women who work in different occupations have different learning opportunities and barriers to adopt ICT. Those who are working in the ICT field might have different set of learning opportunities and other career advancement barriers.

\section{References}

Ariffin, J. 1995, "Reviewing Malaysian women's status: country report in preparation for the fourth UN world conference on women", in Koshal, M., Gupta, A. and Koshal, R. (1998), "Women in management: a Malaysian perspective", Women in Management Review 13.1(1995): 11-18.

Alexander Ardichvili, Vaughn Page and Tim Wentling 2003. "Motivation and barriers to participation in virtual knowledge-sharing communities of practice." Knowledge management 7.1 (2003): 64-77.

Andrea Graf, 2004. "Breaking down barriers." Development and learning in organization 19.4 (2005): 20-22.

Bassi, L. \& McMurrer, D., (2007). Maximizing Your Return on People. Harvard Business Review, March 2007, Reprint R0703H.

Baldwin, T.T, Ford, J.K 1988. Transfer of training: a review and directions for future research, Personnel Psychology, Vol. 41 pp.63-105.

Bacci Newton 2006. "Training and age-diverse workforce." Industrial and commercial training 38.2 (2006): 93-97.

Bassi, L., Gallager, A., \& Schroer, E. 1996. The ASTD Training Data Book. Alexandria, VA: American Society for Training and Development.

Broos, A. 2005, "Gender and information and communication technologies (ICT) anxiety: male self-assurance and female hesitation", Cyber Psychology \& Behavior 8.1 (2005): 21-31.

Cross, C., Linehan 2006, "Barriers to advancing female careers in the high-tech sector: empirical evidence from Ireland", Women in Management Review 21.1 (2006): 28-39.

Darkenwald, G.G., Merriam, S.B. 1982, Adult Education: Foundations of Practice, Harper \& Row Publisher, New York, NY.

David Robotham 2004. "Developing the competent learner." Industrial and commercial training 36.2 (2004): 66-72.

Fides Matzodrof and Mike Green 2000. "Barriers to organizational learning in the chartered surveying profession." Property management 18.2 (2000): 92-113.

Government of Pakistan, 2012-13. Economic Survey of Pakistan, Economic Advisor Wing, Finance Division, Islamabad, p.181, $184-85$.

Government of Pakistan 1998. Population and Housing Census of Pakistan, 1998: Census Bulletin-1. Population Census Organization Statistics Division, Islamabad. Government of Pakistan 2002-003. Economic Survey of Pakistan, Islamabad: Economic Advisor Wing, Finance Division, pp.184-85,

Jonathan S.Swift and Keith Lawrence 2004. "Interactive training for UK SMEs." Development and learning in organizations 18.3 (2004): 26-28.

Junaidah Hashim 2008. "Learning barriers in adopting ICT among selected women in Malaysia." Gender in management 23.5 (2008): 
317-336.

Martin McCracken 2005. "Towards a typology of managerial barriers to learning." Management development 24.6 (2005): 559-575.

Martyn Sloman and Toni Borsattino 2007. "Barriers to progress in learning-a global convergence of concern." Development and learning in organization 21.2 (2007): 14-16.

Peter Dalton, Glen Mynott and Michael Shoolbred 2000. "Barriers to career development within the US profession." Library review 49.6 (2000): 271-277.

Rogers, Everett 1995. Diffusion of Innovations. New York: Free Press. 